\title{
DE LA COMPETENCIA DEL JUEZ ARBITRO ARBITRADOR
}

\section{Roberto Medina Infante \\ Profesor Auxiliar de Derecho Económico \\ Escuela de Derecho de la Universidad Católica del Norte}

Durante nuestro ejercicio profesional hemos intervenido en numerosas oportunidades como juez o como parte (demandante o demandado) en variados litigios arbitrales.

A pesar de ser una materia de aparente simpleza por la abundancia y ausencia de normativas respecto de determinadas materias (valga la paradoja), en el hecho, hay una serie de cuestiones no resueltas o aclaradas las que, de una u otra manera nos han llevado a considerar conveniente esbozar algunos pensamientos en torno a algunos de estos aspectos. Sirven como marco las normas de los artículos 628 y siguientes del Código de Procedimiento Civil y 222 y los que continúan, del Orgánico de Tribunales.

Una de las situaciones que más me ha tocado conocer, es la que dice relación con la amplitud de las facultades que tiene el árbitro arbitrador.

El texto más común de la cláusula compromisoria usada en los contratos, es más - menos el siguiente: "toda dificultad que se suscite entre los contratantes con relación a este contrato o con motivo de su aplicación, interpretación, cumplimiento, validez, nulidad y otra causal cualesquiera, será resuelta por un árbitro que resolverá la dificultad planteada, debiendo actuar sin forma de juicio y como amigable componedor y en contra de las resoluciones que dicte no procederá recurso alguno, ni siquiera los de casación o queja. Designan las partes, desde luego, en tal carácter a don ................. Si faltare dicho árbitro o no quisiera aceptar el cargo y si las partes no pudieren ponerse de acuerdo sobre la persona que deba reemplazarlo, tocará a la Justicia Ordinaria designarlo. En tal evento será árbitro de derecho".

De la cláusula que hemos copiado, fluyen varias condicionantes para la actuación arbitral, las que trataremos de ir dilucidando en este estudio.

En primer término, debemos indagar respecto de qué es lo que significa ser "árbitro arbitrador".

El artículo 223 del Código Orgánico de Tribunales reza a la letra: "el arbitrador fallará obedeciendo a lo que su prudencia y la equidad le dictaren, y no estará obligado a guardar en sus procedimientos y en su fallo otras reglas que las partes hayan expresado en el acto constitutivo del compromiso, y si éstas nada hubieren expresado, a las que se establecen en este caso en el Código de Procedimiento Civil."

De la norma transcrita resulta que, para los efectos de determinar la amplitud de las atribuciones arbitrales, debemos estar, en primer término, a lo que las partes hayan determinado en el acto constitutivo del compromiso para examinar, en ausencia de esas 
normas, cuáles otras aplicar.

De acuerdo con lo que cita don Patricio Aylwin Azócar en su obra Juicio Arbitral, Edit. Jur. de Chile, año 1963,página 150, párrafo 91), los arbitradores o amigables componedores "son los llamados a fallar sin sujeción estricta a las leyes y obedeciendo a lo que su prudencia y equidad le dictaren. Tienen poder para juzgar sin atenerse en el procedimiento a los plazos y formas comunes establecidas para los tribunales y sin ser constreñidos a aplicar las reglas del derecho al fondo del litigio. (Fin de la cita. El subrayado es nuestro).

En lo relativo a "arbitrador", el autor indica más adelante que "su diferencia con los demás jueces está en la libertad que tiene para desentenderse de los mandatos de la ley en esta declaración suya decisoria del pleito y fundarla únicamente en las razones que su conciencia estime más prudentes y equitativas."

Por otra parte la frase, "sin forma de juicio" implica que el árbitro dé a la causa la tramitación que le parezca más acorde con la situación que conoce y ello, sin perjuicio de las normas mínimas que den garantías a las partes de un correcto procedimiento. Si el árbitro, en forma soberana determina seguir la pauta de un procedimiento específico reglado por la ley, ello no significa que cambia su calidad de árbitro arbitrador que actúa sin forma de juicio.

A nuestro entender, uno de los deberes de un árbitro arbitrador que actúa como amigable componedor y sin forma de juicio, debe ser el de restablecer una situación legal desequilibrada o una relación injusta entre las partes.

Don Patricio Alylwin Azócar en su obra ya citada, hablando de la competencia arbitral indica textualmente:

Los árbitros son también competentes para interpretar la cláusula de su designación relativa a su competencia.

El principio de que todo juez lo es igualmente de su competencia, rige respecto de los compromisarios.

A los árbitros legalmente constituidos les toca, por consiguiente, resolver en cada caso si los puntos o cuestiones que se les someten por las partes se hallan comprendidos dentro de la órbita de su competencia.

La interpretación de la cláusula sobre competencia, sea que la haga el árbitro o la Justicia Ordinaria en su caso, debe tender fundamentalmente a averiguar la intención de las partes; conocida ésta claramente, el intérprete deberá estarse a ella más que a lo literal de las palabras (C.C.Art. 1.560.-). (Fin de la cita).

De los comentarios que hemos hecho y de las citas transcritas, resulta que la misión primordial de un juez árbitro, investido de las calidades indicadas, es la de "hacer justicia" aunque ésta entre en contradicción con texto legal expreso.

De lo indicado en el párrafo anterior, me parece conveniente deducir dos situacionés primordialmente importantes:

a) Resulta indudable la conveniencia de preocuparse de quién será el juez árbitro, para resolver las eventuales contingencias futuras que pudieran presentarse entre los contratantes, sobre todo, en aquellos contratos denominados "de adhesión"; y 
b) igualmente los Abogados debemos ser cuidadosos al aceptar cláusulas compromisorias en las cuales se renuncia a recursos en contra de las resoluciones ya que, dependiendo del buen o mal criterio del árbitro que se designe, pueden derivarse consecuencias patrimoniales importantes para alguna de las partes.

Hemos revisado jurisprudencia en el Repertorio.

Aun cuando, en conformidad al artículo 30 , inciso segundo del Código Civil, las sentencias de los tribunales no tienen fuerza obligatoria sino sólo respecto de las causas en que se pronuncian, no es menos cierto que ellas fijan el sentido general en que debe mirarse una disposición legal.

En esta revisión, pudimos observar que la cantidad de sentencias que analiza dicho Repertorio es escasa y ello lo atribuimos al hecho que, la mayoría de las resoluciones dictadas en los juicios arbitrales, no es revisada por los tribunales ordinarios y, por esa circunstancia no podemos saber cuales son los criterios empleados por los jueces árbitros en esta materia.

Util sería que en este repertorio, se incorporaran resoluciones de los juzgados arbitrales, tanto más cuanto que actualmente en el Congreso se está discutiendo un proyecto de ley que otorga mayor relevancia a este sistema, a objeto de descargar de los tribunales ordinarios una parte de su pesada carga de trabajo.

En sentencia de la Corte de Santiago, de 16 de Abril de 1952, comentada en el Repertorio, se señala que; "si bien es propio de los árbitros arbitradores resolver los asuntos sometidos a su conocimiento obedeciendo a lo que la prudencia y equidad les dicten, dicha facultad no puede entenderse a la decisión de una cuestión de competencia". arriba.

El fallo a que hemos aludido, contradice la opinión del tratadista transcrita más

En todo evento, y del estudio particular que hemos hecho del tema, para la redacción de estos comentarios, nos parece importante comentar, a modo de conclusión, las interesantes posibilidades jurídicas que las partes le pueden entregar a este juez, lo que determinaría la mayor o menor amplitud de su accionar y, a la vez resaltar, la poca importancia que se le da a la cláusula compromisoria, al redactar los contratos tanto más cuanto que, con facultades amplísimas en manos de un mal árbitro, podríamos observar posibilidades de importantes desmedros patrimoniales. 